\title{
Lithium Action in the Treatment of Mania Episodes
}

\begin{abstract}
Alcimar Tamir Vieira da Silva ${ }^{1}$, Bruna Michele Soares Santana ${ }^{1}$, Emerson de Souza Bezerra $^{1}$, Alanne Renaly Mota Rodrigues ${ }^{1}$, Poliana Leite Neiva ${ }^{1}$, Arthur da Silva Gouveia Lima ${ }^{1}$, José Diogo dos Santos Gondim $^{2}$, Laura Maria de Araújo Pereira ${ }^{1}$, Talyta Valéria Siqueira do Monte ${ }^{3}$, Janaina Angelo Rufino ${ }^{4}$, Juscelino Kubitschek Bevenuto Silva ${ }^{1}$, Áquila Matheus de Souza Oliveira ${ }^{1}$, Hallysson Douglas Andrade de Araújo ${ }^{5}$, José Guedes da Silva Júnior ${ }^{1 *}$
\end{abstract}

${ }^{1}$ Mauricio de Nassau - Campina Grande Central University

${ }_{2}^{2}$ Secretaria de Municipal de Saude - Serrita - PE

${ }^{3}$ Secretaria de Saúde - Pedras de Fogo - PB

${ }^{4}$ Secretaria de Saúde - Cedro - PE

${ }^{5}$ Federal University of Pernambuco

*Corresponding author: : José Guedes da Silva Júnior, Center for BiosciencesDepartment of Biochemistry, Federal University of Pernambuco, Avenida Prof. Moraes Rego, 1235, Cidade Universitária, Recife-PE 50.670-501, Brazil.

\section{Abstract}

Introduction: Lithium is a chemical element found in magmatic rocks. Although these rocks have been with us since the beginning, only in 1940 did John Frederick Joseph Cade propose the following hypothesis: Manic episodes are triggered by changes in uric acid in the human body, with the use of lithium, cause reduced excitability. Getting success. After fifty years of use, lithium carbon is still an effective treatment for Bipolar Affective Disorder (TAB) and is recognized as an excellent mood stabilizer.

Objectives: This work aims to conduct a panoramic study of the use of lithium in the treatment of BTA, to investigate psychopharmacological uses, clinical management and its role in the human body. In addition to pharmacological performance observations, it also tries to understand the efficacy and therapeutic effects.

Discourse and results: The DSM-IV, aims to describe the most common characteristics, the most diverse symptoms of the most diverse Mental Disorders, dividing itself in a simple but complete way. The DSM-IV diagnosis of Mania requires an understanding of the following issues: abnormally high, expansive or irritable mood lasting at least a week.Lithium has many effects on neurotransmitters. In TAB, it causes complex effects, regulating the balance between the excitatory and inhibitory effects of several neurotransmitters, including serotonin, norepinephrite, glutamate, gamma aminobutyric acid and dopamine.Behavioral sensitivity or reverse tolerance occurs when a medication or other type of drug increases its effect with chronic use, unlike most medications that have the opposite effect.

Conclusion: Finally, the positive role of lithium in the treatment of BD has been confirmed by several randomized clinical studies, among which, lithium has more prominent advantages in preventive treatment, thus preventing the recurrence of Mania and depression. Like all drugs, the use of lithium can bring conflicts and risks during use. Although it has been used for a long time, there are still many issues to be discussed regarding this drug. For the mental health professional, it is important to guide their patients about the disease and the use of the medication.

Keywords: Cerebral venous thrombosis; Cerebral perfusion; Arterial spin labeling; Adverse outcome; Prognosis

\section{Introduction}

Lithium is a chemical element found in magmatic rocks. In the 1940s John Frederick Joseph Cade developed the hypothesis that manic episodes were triggered by changes in uric acid in the body, leading him to perform tests on animals using lithium 
salts, thus verifying a decrease in excitability in these animals. Subsequently, further research was done using lithium for the Treatment of Bipolar Affective Disorder (BD) in humans, achieving satisfactory results. In view of the positive effects of this chemical element, it became the first option in the treatment of bipolar affective disorder. Lithium carbonate, after fifty years of use, continues to be the first-line treatment for patients with BAD, being established through studies and clinical practice as the mood stabilizer par excellence. Guidelines established through evidence, establish lithium as the first therapeutic choice in all stages and presentations of $\mathrm{TB}$, with antipsychotics as a second choice in the treatment of mania and antidepressants the second most used medication in depressive episodes. In view of this important reality, the present study aims to conduct a panoramic research about the use of lithium in the treatment of bipolar affective disorder, ranging from its psychopharmacological use in history, its relevance in the treatment with bipolar patients, its clinical management according to the parameters of DSM-IV and the way it acts on neurotransmitters and human behavior. It also seeks to understand the efficacy and therapeutic action of lithium both in episodes of mania and in the context of depression characteristic of TB, observing its pharmacological action in the characteristic manifestations of patients with bipolar disorder [1-3].

\section{Development}

\section{History of the psychopharmacological use of lithium}

Lithium is a chemical element, represented by the symbol Li, belonging to group IA of the periodic table, in the category that belongs to alkali metals. Its name derives from the Greek term lithos which means stone, being found mainly in the magmatic rocks of the earth's crust, also detected in plants and animal organisms. Its application ranges from the production of medicines to use in the industrial area, for example: battery manufacturing, participation in the operation of cardiac pacemakers, formation of metal alloys, production of lubricants for high temperature machines, formulation of psychiatric drugs against depression bipolar and tranquilizers, among others. Among the many characteristics that this element has, is the recognition of being an extremely reactive material, a good conductor of electricity, a highly flammable element and a metal of lower density, being less dense than water $[4,5]$.

Since ancient times, it was common in society to use water composed of lithium and other alkali metals to treat various types of diseases, including manic arousal, believing that this type of procedure had a high therapeutic degree. Galen, in 200 $\mathrm{BC}$, prescribed baths in alkaline sources for agitated or euphoric patients. Making "Spas" in northern Italy known to these patients' destinations (Georgotas and Gershon, 1981). Just over two thousand years later, they found that these waters were rich in lithium salts.
In the period of imperial Brazil, the governor and scientist, José Bonifácio de Andrade, in his research in Sweden, found mineral compounds hitherto unknown (APUD El-Mallakh, 1996). An alkaline material called petalite, bringing in its composition $4 \%$ of an alkaline metal hitherto unknown. Further research by Swedish chemists Baron Jons Jacob Berzelius and Johan August Arfwedson in 1817. Berzelius named this new metal "lithia" and then British chemist Humphry Davy, the first to isolate this mineral, changed its name to lithium. The initial therapeutic use of lithium in 1840, in the form of carbonate, was intended to treat gout and diseases considered at the time associated with excess uric acid in the body (Garrod, 1859 APUD Mitchell, Hadzi-Pavlovic, 2000) [6,7].

The great moment in the history of lithium occurred in 1954, with the publication of the first study by Danish researcher Mogens Schou and colleagues on the use of lithium in Mania. The use of lithium in bipolar disorder has caused a revolution in psychopharmacology, as it has led psychiatrists to think in terms of diagnosis, since the usefulness of lithium in classical mania has been confirmed by several scientific studies and clinical practice. For a long time lithium was used as the only mood stabilizer, recently other medications have started to be used for this purpose, such as anticonvulsants and atypical antipsychotics. These medications, with different pharmacological, dosage and clinical characteristics, called into question the "reign" of lithium and its current role in the therapeutic arsenal of TB. What is observed in clinical practice is a decline in the use of this medication. Several reasons can be alleged for this: dose difficulties, serious (rare) adverse effects and the investment of the pharmaceutical industry in the development of new medications $[8,9]$.

However, lithium carbonate, after 50 years, remains a first-line treatment for most bipolar patients. Studies and clinical practice still establish lithium as the mood stabilizer par excellence. Guidelines developed through an evidence-based approach make lithium the first therapeutic choice in virtually all stages and presentations of TB.5 It follows that psychiatrists (especially those in training) should be encouraged to know the indications of and learn to use this medication, which has helped so many patients [10].

\section{DSM-V criteria for diagnosis of Mania}

The DSM-V aims (like the other versions) to describe the most common characteristics, that is, the symptoms of the most diverse Mental Disorders, dividing itself in a simple but complete way. Through this Manual it is possible to make a more accurate diagnosis, helping decisively in the treatment of any disorder. The diagnosis of Mania (which is within the type I bipolar disorder) by DSM-V requires understanding of issues such as: persistent and abnormally elevated, expansive or irritable mood lasting at least a week. If hospitalization is required before a week, the diagnosis can also be made. In addition to the change in mood, 
at least three (or four if the mood is irritable) of the following symptoms must be present: greatness, decreased need for sleep, pressure to speak, emotional dullness, flight of ideas or running thoughts, distractability, increased activity directed towards goals or psychomotor agitation, excessive involvement in pleasurable activities (Moreno, Moreno and Ratzke, 2005). A major failure of this classification is not to mention psychotic symptoms among the criteria, and yet another failure is to rule out, in view of the diagnosis, the manic episodes induced by antidepressants.

ICD-10 brings in its structure very vague mentions regarding the diagnosis of mania, despite superficially bringing the classification of mania with the absence or presence of psychotic symptoms. After an analysis of the conceptualization carried out by the ICD10, Akiskal et al. (2001) proposed new criteria for the diagnosis of mania. They emphasized psychomotor activation as central to mania, depressed or anxious mood, as well as euphoric or irritable, lack of criticism and four of the following symptoms: increased energy, decreased need for help, greatness, excessive sociability, increased libido, escape from ideas and distractability. The similarity of some symptoms of bipolar disorder to the symptoms present in depression, for example, prevent the disorder from being more easily identified by the psychiatrist. According to (Akiskal et al., 2000) other factors also interfere with the failure to recognize mania, hypomania and mixed states, such as: not investigating hypomania; confusing psychotic symptoms with schizophrenia or hypomanic symptoms with normal behaviors; do not distinguish between mixed episodes of personality disorders, impulsivity with bulimia or with a disorder associated with substance use; and do not consult the informant or use other data sources.

\section{Risk factors for Mania}

Bearing in mind that manic episodes can appear at different times in an individual's life, it is important to highlight the possible factors that can trigger a manic episode. Bipolar disorder is a complex and multidetermined disorder, caused by the interaction of genetic and environmental factors (Bosaipo, Borges, Juruena, 2017, p.75). According to Moreno et al., (2005) episodes of mania can be triggered by the exacerbated use of drugs or abstinence from them. Neurological diseases such as strokes, head trauma, Huntington's disease and epilepsy can trigger mania, in addition to endocrine and metabolic diseases, such as hyperthyroidism. Another predominant factor is the question of the age at which these episodes can happen, in a more universal way the first episodes occur in the migration from adolescence to the beginning of adulthood (between 18 and 25 years), it is not known why the manic episodes occur at this stage, requiring further studies in this regard.

Although not evaluated in community studies, family history must be included as an important risk factor. The relationship between Bipolar Disorder (TB) and family history is well established and the risk of TB is consistently increased in firstdegree relatives when compared with normal controls or with major depression. (Lima, Tassi, Novo, Mari, 2005, p. 19). There is no consensus among researchers as to what are the real causes of manic episodes, whether they are transmitted from generation to generation, whether there is a gene that is partially responsible, or whether the causes are fully triggered by situations that have occurred with these individuals.

\section{Effects of lithium on electrolytes and ionic transport}

Lithium is an alkali metal, with physico-chemical properties very similar to those of sodium, potassium, magnesium and calcium with multiple pharmacological activities, including effects on embryonic development, glycogen synthesis, hematopoiesis and other biological processes (Faria, 2017, p .23). Lithium (Li) has some similarities with the sodium element $(\mathrm{Na}+)$ present in the $\mathrm{Na}+/ \mathrm{K}+$ pump, has a similar ionic radius, and can replace sodium $(\mathrm{Na}+)$ in the generation of action potentials. However, lithium cannot be pumped at the same speed as the $\mathrm{Na}+/ \mathrm{K}+$ pump, and this results in the greater accumulation of this ion inside the cell, making sodium substitution $(\mathrm{Na}+)$ unfeasible. However, even though its performance is not complete, there is a change in membrane permeabilization, thus relating to anti-manic action (Feldman, Meyer, Quenzer, 1997).

However, at concentrations below $(1 \mathrm{mmol})$ it will not interfere with $\mathrm{Na}+/ \mathrm{K}+/$ ATPase pumps and $\mathrm{Na}+/ \mathrm{Ca}++$. In its action in the body, lithium causes the decoupling of thyroid stimulating hormone (TSH) from its receptor to occur, hindering the production and distribution of T3 and T4 to the body. Birch (1999) says that, due to interactions with magnesium, which functions as a cofactor for a large number of enzymes, lithium can inhibit various metabolic processes (for example, glycolysis). Taking into account other effects of lithium on electrolytes, Feldman et al., (1997) argue that competing with calcium, lithium can affect actions dependent on this ion such as the release of neurotransmitters and the production of cyclic Adenosine Monophosphate (AMPc) and modify the calcium-mediated second messenger system.

\section{Effects of lithium on neurotransmitters: NA, ACH. 5-HT (Noradrenaline NA; acetylcholine (ACh); serotonin (5- HT)}

There are many effects of lithium on neurotransmitters. In bipolar disorder, it results in a complex action modulating the balance between the excitatory and inhibitory effects of several neurotransmitters, among them serotonin (5-HT), norepinephrine (NE), glutamate, gamma aminobutyric acid (GABA) and dopamine (GIVES); interfering in secondary messenger systems (adenylcyclase and phosphoinositol) with effects on $G$ proteins and protein C-kinase; inhibiting the activity of certain enzymes, such as kinase 
3-glycogen synthase (GSK-3), due to competition with magnesium. The proposed mechanism of action to enhance its antidepressant effect refers to effects on serotonergic neurotransmission. Lithium can act as a partial agonist or exert modulating activity on 5-HT1B autoreceptors located in the cortical area, in short-term treatments, or in the hippocampus, if its use is prolonged. The anti-mania effect would also be associated with the action on 5-HT1B receptors, in this case in postsynaptic (heteroreceptors in dopaminergic pathways).

According to (Howland, 2007), although lithium has many neurobiological effects, its mechanism of action in bipolar disorder is not well understood. It works by normalizing the reuptake of certain neurotransmitters, such as norepinephrine, acetylcholine, serotonin and dopamine. It also reduces the release of norepinephrine through calcium. Lithium produces effects within cells and not within neural synapses; acting directly on protein G, on certain enzyme subsystems, such as cyclic adenosine monophosphate and phosphatidylinositol. Lithium acts by intensifying some serotonin actions; increasing the release of 5-HT, especially in the hippocampus. It has variable effects on norepinephrine, which may slightly alter the reuptake and presynaptic storage of catecholamines. It inhibits the release of norepinephrine and $\mathrm{Ca}++$-dependent dopamine, seeking to block the development of dopamine receptor supersensitivity, increasing the synthesis of acetylcholine, possibly by facilitating the uptake of choline by nerve endings by increasing the release of acetylcholine. Studies indicate that lithium can inhibit noradrenaline-sensitive adenylylcyclase, having an action on inositol phosphates, inhibiting the calcium-mediated cellular response.

\section{Effects of lithium on behavioral awareness}

Behavioral sensitization or reverse tolerance occurs when a medication or other type of drug increases its effect with chronic use, unlike most medications that have the opposite effect. It is believed that the development of behavioral sensitization is related to the increased release of dopamine (neurochemical process) in the nucleus accumbens, generating lasting behavioral hypersensitivity (STEKETEE and KALIVAS, 2011; HYMAN et al., 2006; VALJENT et al., 2006; ROBINSON and BERRIDGE, 1993). Vezina (1996) reports that the use of certain dopaminergic antagonists can inhibit the development of behavioral sensitization, which reinforces the participation of dopaminergic receptors in this process. According to some studies, lithium has the ability to regulate and maintain cases of mania (depressing the Central Nervous System) as well as in the treatment of depressive episodes within Bipolar Disorder (Elevating the Central Nervous System). However, care must be taken with the dosage of lithium, as this will vary from patient to patient, if there is an error the patient may suffer from intoxication (as time goes by, there will be no instant intoxication), as well as it may happen that the dosage administered is very low, not causing the expected effect, which would be the reduction of symptoms (be it manic episodes or depressive episodes within bipolar disorder). Finally, lithium is a good medicine for the treatment of manic episodes and depressive episodes, however it is vital to have control of the dosage and verification of side effects in patients for the treatment to be successful.

\section{Conclusion}

Finally, the positive impact of the use of lithium in the treatment of bipolar affective disorders is confirmed by several randomized clinical studies, in which lithium is superior in questions related to prophylactic treatment, thus avoiding recurrences of manic and depressive episodes, in addition to exert an effective anti-suicidal effect. Being one of the most effective psychotropic drugs, easily accessible to the population due to its low production cost. Like all medication, the use of lithium can present contraindications and risks during the period of use. It can cause common or even chronic adverse reactions, being necessary on the part of health professionals to have a serum monitoring to prevent intoxication of the patient and the appearance of other comorbidities that may develop as a result of the interaction with other drugs, mainly in the renal, gastrointestinal system. and hormonal. Despite the time of use, there are still many issues that need to be discussed about this medication, and it is important for mental health multiprofessionals to guide their patients about the disease and about the use of the medication. Also needing to do periodic medical monitoring and close relationships to assess the progress of the disease or its stabilization and together with pharmacological treatment, associate other possible treatment alternatives such as psychological therapy, among others.

\section{Acknowledgement}

None.

\section{Conflict of Interest}

No conflict of interest.

\section{References}

1. BIRCH, Nicholas J (1999) Inorganic Pharmacology of Lithium. American Chemical Society 99: 2666-2676.

2. BOSAIPO NB, BORGES VF, JURUENA MF (2017) Transtorno bipolar: uma revisão dos aspectos conceituais e clínicos. Medicina (Ribeirão Preto, Online) 50(1): 72-84.

3. FARIA, Débora da Cruz (2020) Importância do Lítio no Tratamento do Transtorno Afetivo Bipolar. 2017. 48 f. Monografia (Graduação em Química Industrial) - Instituto Municipal de Ensino Superior de Assis IMESA e a Fundação Educacional do Município de Assis - FEMA, Assis, 2017. Disponível em.

4. Feldman RS, Meyer JS, Quenzer LF (1997) Principles of Neuropsychopharmacology. 1a edition. Massachussetts: Sinauer Associates Inc. Publishers: 853-859.

5. GAZALLE, Fernando Kratz, KAPCZINSKI, Flávio (2006) Mogens Schou e o uso do lítio em psiquiatria. Revista Brasileira de Psiquiatria 28(1). 
6. Lima MS de, Tassi J, Novo IP, Mari JJ (2005) Epidemiologia do transtorno bipolar. Revista de Psiquiatria Clínica 32(1): 15-20.

7. Moreno RA, Moreno DH, Ratzke R (2005) Diagnóstico, tratamento e prevenção da mania e da hipomania no transtorno bipolar. Revista de Psiquiatria Clínica 32(1): 39-48.

8. Sadock BJ, Sadock VA, Ruiz P (2017) Compêndio de Psiquiatria- Ciência do Comportamento e Psiquiatria Clínica. 11르ed. São Paulo: Editora ARTMED LTDA.

9. SANGUEDO, Francisco Velasco Costa (2020) O Efeito do Desenvolvimento da Sensibilização Comportamental na Ativação da Proteína ERK em Estruturas Cerebrais Relacionadas à Dependência Química. 2013. 101 f. Dissertação (Mestrado em Ciência Animal) - Centro de Ciências e Tecnologias Agropecuárias, Universidade Estadual do Norte Fluminense Darcy Ribeiro, Campos dos Goytacazes, 2013. Disponível em: < http://uenf.br/posgraduacao/ciencia-animal/wp-content/uploads/ sites/5/2015/10/Disserta\%C3\%A7\%C3\%A3o-Frederico-Velasco.pdf>. Acesso em: 12 de maio de.

10. ZUNG Stevin, MICHELON, Leandro, CORDEIRO, Quirino (2010) 0 uso do lítio no transtorno afetivo bipolar. Arquivos Médicos dos Hospitais e da Faculdade de Ciências Médicas da Santa Casa de São Paulo, 55(1). 